\title{
Hand Operated Mechanical Coffee Heater
}

\author{
Jayaram A S \\ Associate professor \\ Department of Mechanical Engineering \\ Dr. Ambedkar Institute of Technology \\ Bangalore, Karnataka. \\ India.
}

\begin{abstract}
The mechanical heater is purely based on the frictional concept. Friction is the force resisting the relative motion of solid surfaces, fluid layers, and material elements sliding against each other. Friction is not always unwanted. Friction is required for us to walk. Winter car tires usually have deeper treads than regular tires. The extra grooves make the surface rougher and help them get a grip on ice and snow. Here the heat generated by friction is utilized. In this model, the heat is generated due to surface friction between the brake lining and steel Cup. There are two form of heat transfer take place namely conduction in steel cup and Convection from steel to solution. Heat transfer takes place as conduction initially from brake linking to cup by conduction. From the surface of the cup to the liquid inside the cup, heat is transferred mainly by convection. The simple hand drill equipment is used to increase the speed of rotation of the outer cup. This equipment is only hand operated and hence will not require any electricity or fuel to run. Generating friction by rotation of gears manually and in turn, rotates a disc which would be in contact with another stationary disc. The heat will be generated as a result of friction another stationary disc should be a container a vessel side portion so that when the disc is in friction with the vessel surface, the heat generated can be used for heat the water or coffee contained in the vessel. Hence it can be used in very cold countries or near Polar Regions to easily heat a cup of coffee.
\end{abstract}

Key Words: Friction, Heater, Mechanical, Coffee.

\section{INTRODUCTION}

In this project, readily available simple materials are used to get frictional heat for heating a cup of coffee with human effort. The fabrication also is very simple and overall cost less than 2000 INR. Even then it is highly reliable and very simple to operate. Only alternative is to use a small generator to generate electricity and then use it to heating coffee. But the manual energy lost in conversion of mechanical energy to electrical energy is $20 \%$ because the efficiency of a good generator is about $80 \%$. Also, the fabrication will be difficult and cost will be more than three times of this. The weight and size will also be more.

\section{MATERIALS USED}

\subsection{The hand drill}

This is the main component used for increasing the speed from manual rotation to the cup through the bevel gear and pinion mechanism. The rate at which a person can rotate the handle of the drill is about 8 to $10 \mathrm{rpm}$, This will increase to 40 to $50 \mathrm{rpm}$ by 5:1 diameter ratio of bevel gears. The gear will be having about $100 \mathrm{~mm}$ diameter and the two pinions are of equal diameter of about $20 \mathrm{~mm}$ each, as shown in figure 1 . 
Jayaram. A S , Hand Operated Mechanical Coffee Heater

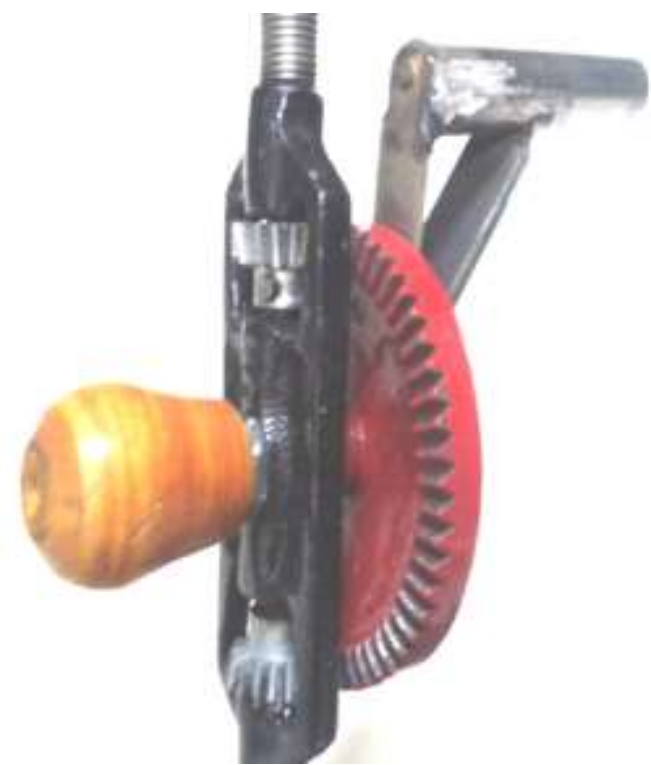

Figure 1. Hand drill showing bevel gears.

\subsection{Brake lining material}

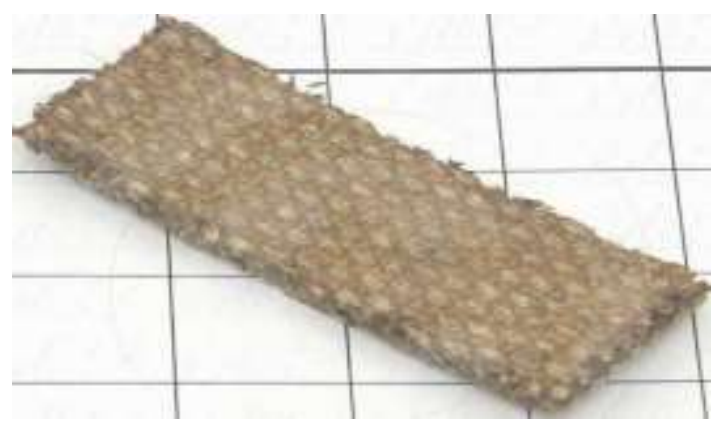

Figure 2. Brake lining material

Brake linings are the rough surfaces in brake systems, such as drum brakes and disc brakes used in transport vehicles. Brake linings are composed of a relatively soft but tough and heat-resistant material with a high coefficient of dynamic friction and ideally an identical coefficient of static friction. These typically mounted to a solid metal backing using high-temperature adhesives or rivets.

\subsection{Outer metal cup}

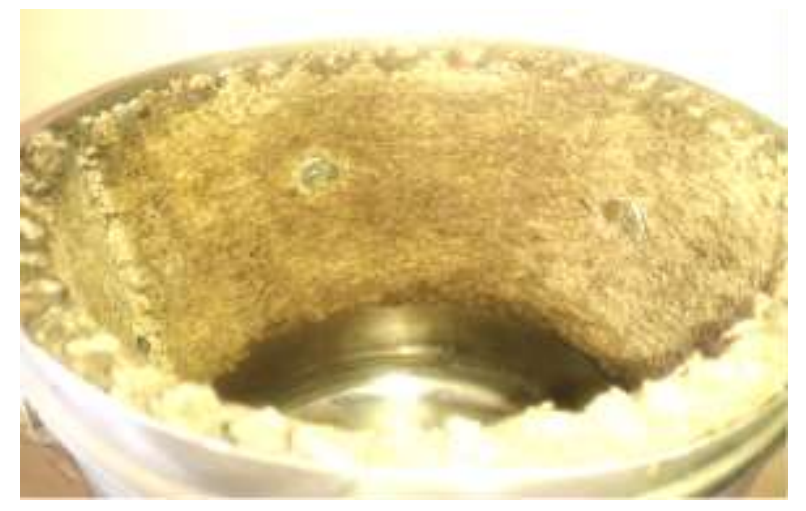

Figure 3 Fixing brake lining material inside the outer cup. 
Brake lining are excellent in stability, having high friction coefficient, low wear giving longer performance life, drum compatibility, superior fade recovery, water resistance, low speed sensitivity. The woven brake lining is fixed inside the cup surface using bolts and nuts as shown in the above fig. 3 .

\subsection{Inner cup}

The inner cup is any stainless steel cup with suitable size to fit the outer cup correctly. This is actually the container which holds the coffee. So, it is just force fitted in to outer cup and held in position to prevent rotation by frame and clamp arrangement.

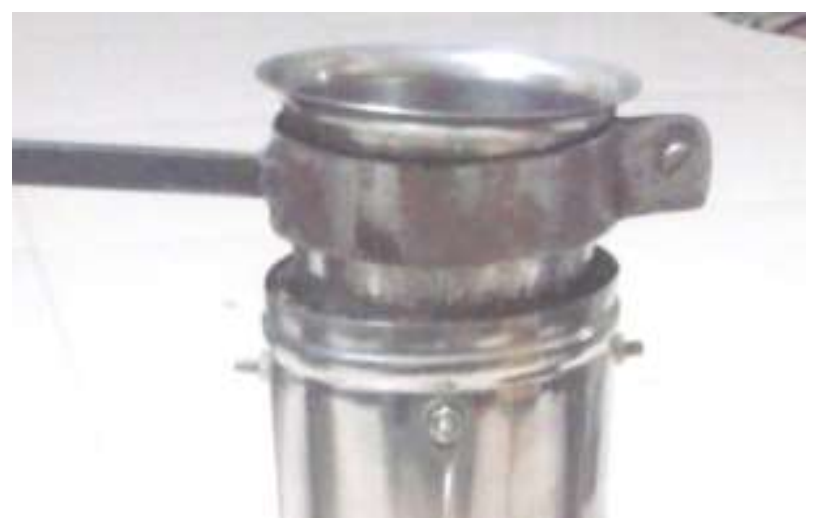

Figure 4. Preventing the inner cup from rotation

\subsection{Supporting frame.}

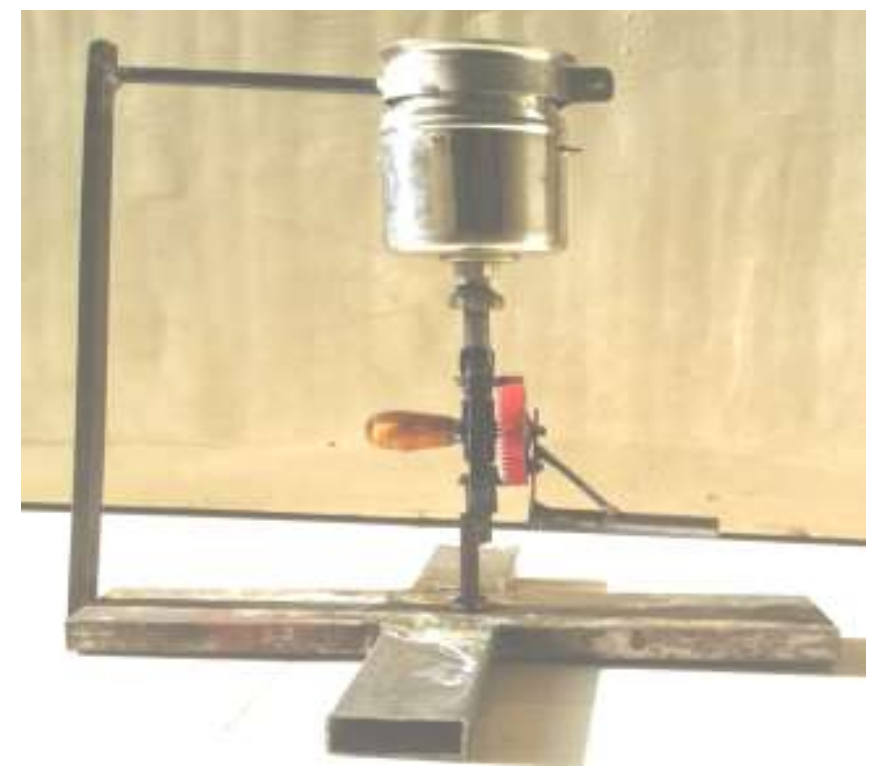

Figure 5. Supporting frame in the equipment

It is the main frame supporting the components. The base portion is of frame is in the form of a plus mark as shown in figure-5. It is made from mild steel. A vertical rod is welded to it. This vertical rod is supporting a horizontal rod with clamp to hold the coffee cup.

\section{FABRICATION OF THE EQUIPMENT}

The Hand drill can be used to convert vertical rotation into horizontal rotation; hence it is suitable for this project. The chuck of the hand drill is removed. The Woven brake lining is cut according to the required length and fitted inside the cup through nuts and bolts as shown in fig.6. By rotating drive wheel of the hand drill, the rotation is imparted to the brake lined cup. The brake lined cup is axially welded to the chuck screw of the hand drill by electric arc welding. This arrangement is welded into the metal bed. 


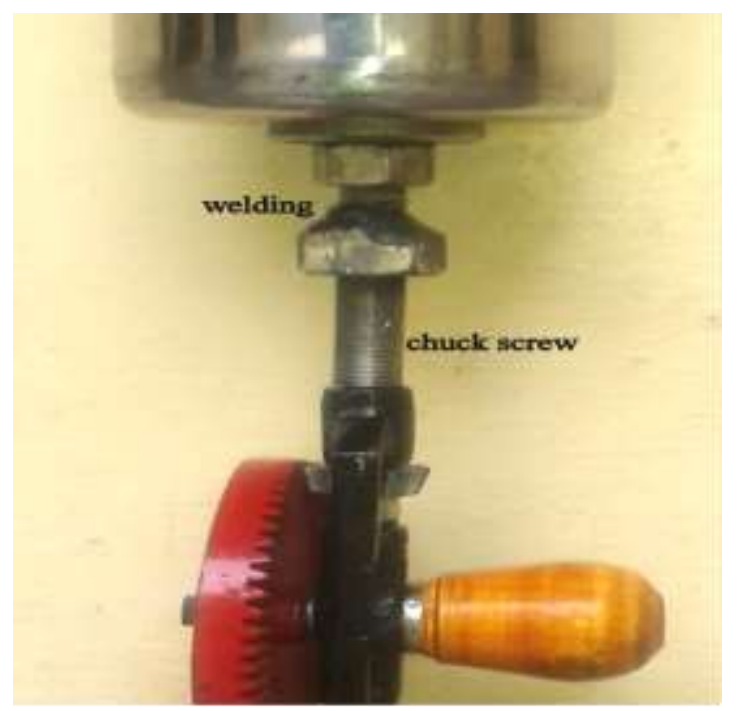

Figure 6. Welding of brake lined cup to the chuck screw

Coffee container is the steel cup which is held by the clamp. The rubber lining is placed between steel cup and clamp for firm holding, and it is welded to a horizontal metal rod. Further this holder is welded perpendicular to the vertical metal rod which is welded to the metal base. The metal base provides rigidity and strength between hand drill and holder.

\section{WORKING MECHANISM.}

The working mechanism of the mechanical heater begins with rotating the turning handle connected to the drive wheel. It imparts its vertical rotation into horizontal rotation of pinions in the bevel gear arrangement as shown in the above fig. Bevel gears are used to transmit motion between shafts with intersecting center lines. The intersecting angle is normally 90 deg but may be as high as $180 \mathrm{deg}$. When the mating gears are equal in size and the shafts are positioned at 90 degrees to each other, they are referred to as miter gears.

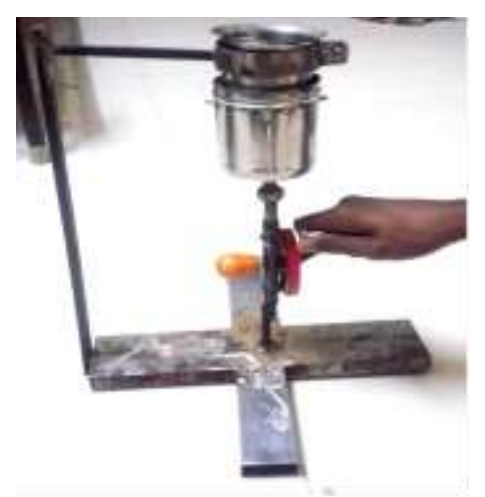

Figure 7. Working mechanism

The teeth of bevel gears can also be cut in a curved manner to produce spiral bevel gears, which produce smoother and quieter operation. The rotation of the brake lined cup generates surface friction over the outer surface of the fixed steel cup. Hence heat generated due to that friction. The heat generated is conducted from outer surface into the inner surface of the fixed steel cup. Further this heat flows due to convection into the solution inside the fixed steel cup and hence the solution gets heated up to the required amount. 
International Journal of Advances in Scientific Research and Engineering (ijasre), Vol 4 (9), September - 2018

\section{EXPERIMENTAL PROCEDURE.}

Initially, the cup was filled with $150 \mathrm{ml}$ of water and the initial temperature was noted down. The drill handle was rotated manually, till an increase of temperature of $3^{0} \mathrm{c}$. Then the experiment was repeated for $250 \mathrm{ml}$ and $500 \mathrm{ml}$ of water for the same rise in temperature. Each time the number of rotations and the corresponding times were noted down.

6 RESULTS AND DISCUSSION.

Table 1. Showing time taken to rise $3^{0} \mathrm{c}$ for different quantities of water and coffee

\begin{tabular}{|c|c|c|c|c|c|c|c|}
\hline Sl No & $\begin{array}{c}\text { Type } \\
\text { of } \\
\text { liquid }\end{array}$ & $\begin{array}{l}\text { Quantity } \\
\text { of liquid }\end{array}$ & $\begin{array}{c}\text { Initial } \\
\text { temperature }\end{array}$ & $\begin{array}{c}\text { Final } \\
\text { temperature }\end{array}$ & $\begin{array}{c}\text { Rise in } \\
\text { temperature }\end{array}$ & $\begin{array}{c}\text { Number of } \\
\text { rotations }\end{array}$ & $\begin{array}{l}\text { Time in } \\
\text { minutes }\end{array}$ \\
\hline 1 & \multirow{3}{*}{ Water } & 150 & 27 & 30 & 03 & 50 & 05 \\
\hline 2 & & 250 & 27 & 30 & 03 & 75 & 09 \\
\hline 3 & & 500 & 27 & 30 & 03 & 145 & 17 \\
\hline 4 & \multirow{3}{*}{ Coffee } & 150 & 27 & 30 & 03 & 60 & 06 \\
\hline 5 & & 250 & 27 & 30 & 03 & 80 & 10 \\
\hline 6 & & 500 & 27 & 30 & 03 & 152 & 18 \\
\hline
\end{tabular}

The experimental results are tabulated as shown in the table -1 . The number of rotations by hand also are tabulated.

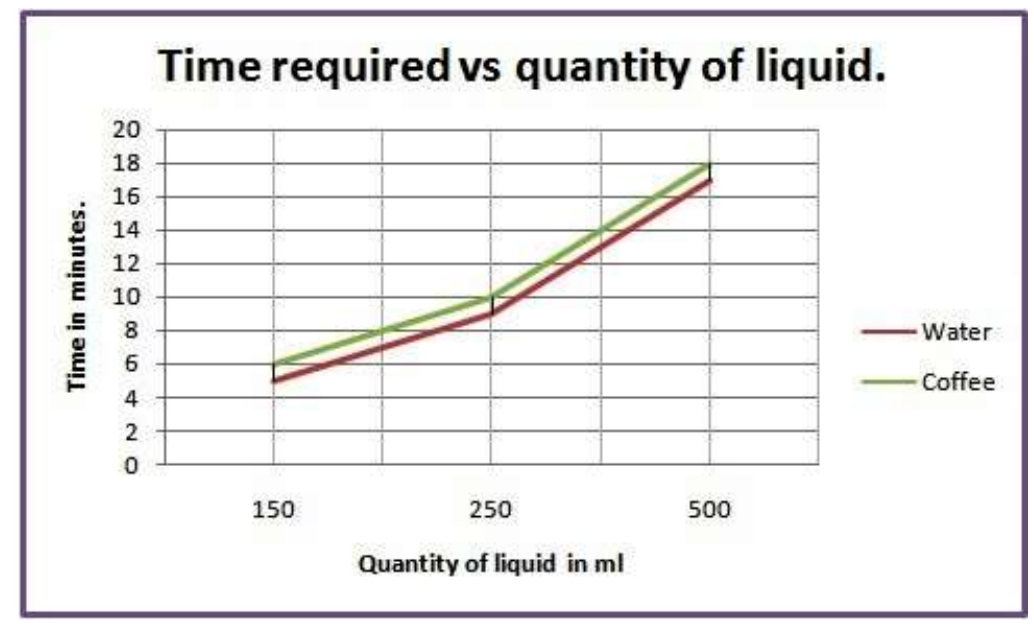

Figure-8.Graphs showing time required for different quantities of liquids

The graph in figure- 8 shows the number of turns (by hand) required to rise 30 rise of temperature of water and coffee. For pure water, number of turns or energy required is slightly less compared to coffee because; addition of solvents to water increases the specific heat of water slightly. 


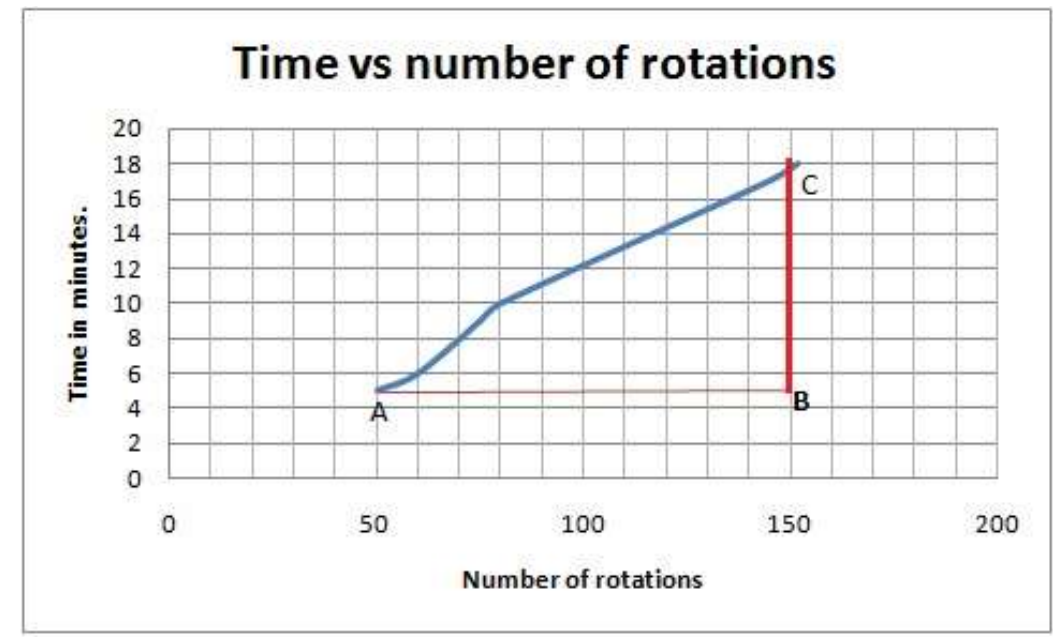

Figure-9.Graphs showing time vs number of manual rotations

Graph in figure-9 shows almost linear relationship between time and manual rotation. Slope indicates that rate of rotation or is approximately $8 \mathrm{rpm}$. This is because of lot of friction purposely made from brake lining to generate heat.

\section{SCOPE FOR FURTURE WORK.}

There is a possibility to increase the generation of heat by replacing pedal system in the place of hand drill arrangement. Time required to heat a solution can be minimized by the replacement of steel cup by copper. The frame can be made by a lighter material like aluminium to reduce the total weight.

\section{CONCLUSION}

Nowadays everything is dealing with the electricity, and in some situations or places the availability of the electricity is difficult, in order to overcome this mechanical heater helpful in the field of solution heating. This device is cheap, portable, and handy. It can be used in remote areas as heating device, as kitchen equipment etc.

\section{ACKNOWLEDGMENT}

I sincerely thank my college, Dr Ambedkar Institue of technology for helping the students to fabricate the product. I thank my students and in particular, Sudhee K N , who took interest in doing this project.

\section{REFERENCE}

[1]. "Leonhard Euler". Friction Module. Nano World website. 2002. Retrieved 2011-03-25.

[2] Van Beek, Anton. "History of Science Friction". Retrieved 2011-03-24.

[3] Armstrong-Hélouvry, Brian (1991). Control of machines with friction. USA: Springs.

[4] Ruina, Andy; Rudra Pratap (2002). Introduction to Statics and Dynamics. Oxford University Press. p.713.

[5] Meriam, J. L.; L. G. Kraige (2002). Engineering Mechanics (fifth ed.). John Wiley \& Sons. 